\title{
A falta de informação sobre os Organismos Geneticamente Modificados no Brasil
}

\author{
The lack of information on Genetically Modified Organisms in Brazil
}

Isabelle Geoffroy Ribeiro ${ }^{1}$

Victor Augustus Marin ${ }^{2}$

${ }^{1}$ Instituto de Pesquisa

Clínica Evandro Chagas

(IPEC), Fundação Oswaldo

Cruz Fiocruz (Fiocruz). Rua

Leopoldo Bulhões 1480,

Manguinhos. 21041-210

Rio de Janeiro RJ.

isa_geoffroy@yahoo.com.br

${ }^{2}$ Núcleo de Inovação

Tecnológica do Instituto

Nacional de Controle e

Qualidade em Saúde,

Fundação Oswaldo Cruz

Fiocruz (Fiocruz)

\begin{abstract}
This article presents a review about the labeling of products that have Genetically Modified Organisms (GMO), also called transgenic elements in their composition. It addresses the conventions, laws and regulations relating to such products currently governing the market, the adequacy of these existing standards and their acceptance by society. It also examines the importance of the cautionary principle when assessing the application of new technologies or technologies where little is known or where there is no relevant scientific knowledge about the potential risks to the environment, human health and society.
\end{abstract}

Key words Transgenics, Risk, Labeling, Biosecurity
Resumo O presente artigo apresenta uma revisão sobre a rotulagem de produtos que apresentem em sua composição Organismos Geneticamente Modificados (OGM), também denominados de transgênicos. São abordadas as convenções, as leis e as normas referentes a esses produtos dispostos no mercado, a adequação dos mesmos às normas vigentes e sua aceitação pela sociedade. Dispõe também sobre a importância do princípio da precaução na avaliação da aplicação de novas tecnologias ou de tecnologias das quais não se conhece ou existam conhecimentos científicos relevantes quanto aos seus potenciais riscos ao meio ambiente, à saúde humana e à sociedade.

Palavras-Chave Transgênicos, Risco, Rotulagem, Biossegurança 


\section{Introdução}

O avanço da ciência nos últimos anos proporcionou a descoberta de novas tecnologias, como as biotecnologias, que são um passo de essencial importância para o progresso da humanidade. O surgimento de novas substâncias e o aperfeiçoamento de novas técnicas proporcionam a descoberta de curas de doenças, fatores inerentes ao avanço na área da saúde.

Todavia, o desenvolvimento de novas tecnologias não se restringe à área da saúde. No campo agroindustrial, os Organismos Geneticamente Modificados (OGM) são considerados um avanço importante para a melhoria e para o aumento do processo produtivo.

De fato, a criação das plantas geneticamente modificadas pode ser considerada um avanço científico e uma certeza de lucro para os grandes centros de biotecnologias e para os produtores rurais, já que confere a elas, por meio da tecnologia do DNA recombinante, características que não seriam adquiridas através do melhoramento convencional.

Acoplado ao desenvolvimento e à introdução no mercado de novas tecnologias nascem novos riscos, gerando dúvidas e insegurança na sociedade de um modo geral, já que estudos de avaliação do risco de uso dessas biotecnologias, em longo prazo, para a saúde humana e para o meio ambiente ainda são incipientes e controversos. Essas incertezas científicas ocasionam polêmicas e conflitos entre os grupos da sociedade favoráveis e aqueles contra a aplicação prática dessas novas tecnologias.

Diante desse contexto, em 2000, foi estabelecido através do Protocolo de Cartagena, de referência internacional, o Princípio da Precaução, que visa, entre outras coisas, a proteção da diversidade biológica e da saúde humana em relação aos danos advindos da liberação dessas novas tecnologias, como os $\mathrm{OGM}^{1}$. O Princípio da Precaução, ainda, estabelece normas-padrão de biossegurança, e institui a rotulagem dos AGM como forma de rastreabilidade desses produtos.

Portanto, a avaliação de risco de consumo desses produtos deve ser realizada assim como devem ser analisadas as normas de biossegurança, para que, desse modo, esses alimentos sejam consumidos de forma mais segura. A biossegurança é definida, segundo a Food and Agriculture Organization $(\mathrm{FAO})^{2}$, como "o uso sadio e sustentável em termos de meio ambiente de produtos biotecnológicos e suas aplicações para a saúde humana, biodiversidade e sustentabilidade am- biental, como suporte no aumento da segurança alimentar global". Além disso, é fundamental que informações sobre esse tipo de produto, consumido em forma de alimento, cheguem à população da forma mais clara possível. Uma vez que o rótulo dos produtos é considerado o principal veículo de informação entre o produtor e a sociedade - consumidor, é imprescindível que a rotulagem dos alimentos transgênicos esteja em conformidade com a legislação vigente ${ }^{2}$.

Nos últimos anos, portanto, estão cada vez mais frequentes os debates socioeconômicos sobre o consumo e os possíveis riscos advindos dos alimentos geneticamente modificados (AGM).

Dessa maneira, o presente trabalho justificase pela necessidade de fornecer informações e ampliar as discussões, no âmbito da saúde humana, sobre os OGM, buscando destacar a importância da utilização do rótulo como ferramenta de informação, além de destacar a utilização do princípio da precaução como ferramenta na análise da aplicação de novas tecnologias, ou das já existentes, diante de seus possíveis efeitos no meio ambiente, na saúde humana e na sociedade.

\section{Organismos Geneticamente Modificados: contexto brasileiro}

Atualmente, vivemos em um período caracterizado pelo alto desenvolvimento científico e tecnológico. Período este, fundamentado em incertezas oriundas dos processos tecnológicos das últimas décadas ${ }^{3}$.

No entanto, os OGM são frutos dessas novas tecnologias - biotecnologias. A biotecnologia é definida, segundo o informe publicado pela Organização de Cooperação e Desenvolvimento Econômico ${ }^{4}$, como "a aplicação de princípios científicos e técnicos ao tratamento de matérias por agentes biológicos para obter bens e serviços”. Ainda de acordo com essa definição, os agentes biológicos são: microorganismos, células animais e vegetais e enzimas. E os bens e serviços são produtos das indústrias do ramo de alimentação, bebidas, farmácia e biomedicina ${ }^{5}$.

Os OGM são aqueles organismos, no caso as plantas, que têm seu material genético modificado pela introdução de um ou mais genes através da técnica de biologia molecular. Assim, genes oriundos de diferentes vegetais, animais ou microorganismos podem ser introduzidos em um genoma vegetal receptor, conferindo às plantas, novas características para a otimização da produção de alimentos, fármacos e outros produtos industriais ${ }^{6}$. 
Há muitos anos, plantas são cultivadas por meio da manipulação genética, mas, só recentemente, a biotecnologia passou a ser considerada prioritária, por ser um instrumento de extrema valia e poder, determinador de progressos e ao mesmo tempo causador de incertezas ${ }^{7,8}$.

A década de 1970 ficou marcada pelos grandes avanços que ocorreram na biologia molecular e na genética, proporcionando o atual progresso e o desenvolvimento biotecnológico. A partir desse momento, micróbios, vegetais e animais, passaram a ser produzidos por transgenia.

Já na década de 1980 e 1990, as biotecnologias passaram a ser objeto de diversas pesquisas e de intensas discussões no âmbito internacional. Segundo Monquero ${ }^{7}$, baseado no relatório da FAO, os primeiros experimentos de campo foram desenvolvidos em 1986 nos Estados Unidos e na França. Já a China foi o primeiro país a comercializar plantas transgênicas no início da década de 90, com a introdução do fumo resistente a vírus, seguido pelo tomate resistente a vírus. No Brasil, a liberação da soja transgênica acha-se regulada desde 1995 pela Lei de Biossegurança no ${ }^{\circ} 8.974$ revogada pela Lei 11.105 de 2005 que fixa as normas coordenadas pela Comissão Técnica Nacional de Biossegurança (CTNBio) para uso dessa técnica de engenharia genética ${ }^{9}$.

Nos últimos anos, diversas variedades de plantas geneticamente modificadas foram aprovadas e introduzidas para a plantação como, por exemplo, a soja, o milho, a canola e o algodão ${ }^{10-11}$. Dentre essas plantas, a mais comercializada é a soja Roundup Ready, cuja patente pertence à empresa multinacional norte-americana Monsanto, que foi desenvolvida através da introdução de um gene oriundo de uma bactéria do gênero Agrobacterium, pertencente ao solo, para aumentar a tolerância ao herbicida glifosfato ${ }^{12}$.

No Brasil, o cultivo de plantas geneticamente modificadas se iniciou no fim da década de 1990 durante o governo de Fernando Henrique Cardoso. A soja transgênica foi plantada ilegalmente no Brasil, Rio Grande do Sul, através de contrabando vindo da Argentina, onde a mesma já era plantada em larga escala. Logo, a soja Roundup Ready seria objeto da primeira solicitação de autorização para cultivo transgênico em escala comercial no país, recebendo, na sequência, parecer favorável da CTNBio ${ }^{13}$. Após a autorização concedida por esta, o Greenpeace e o Instituto de Defesa do Consumidor (IDEC), entraram com

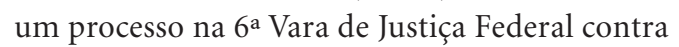
a Monsanto e o governo federal. Esse processo marcou o início da moratória judicial para liberações comerciais de transgênicos no Brasil e fez com que as variedades transgênicas permanecessem fora do mercado entre 1998 e $2003^{14}$.

A fim de resolver o impasse gerado pelas lavouras ilegais de soja transgênica o governo do presidente Luis Inácio Lula da Silva, cedendo à pressão por parte da Monsanto, do Rio Grande do Sul e dos produtores que haviam plantado soja ilegalmente no Brasil, autorizou em 26 de março de 2003 a Medida Provisória 113 que permite o uso comercial dessa soja ilegal para consumo humano e animal destinado à comercialização no mercado interno ou externo, até janeiro de $2004^{14}$.

Cabe destacar que durante esse período de nove anos, entre 1996 e 2004, a área total cultivada com lavouras transgênicas cresceu mais de 47 vezes, passando de 1,7 milhão de hectares em 1996 para 81,0 milhões de hectares em 2004. Nesse mesmo período, o número de países que cultivam plantas transgênicas aumentou de 6 para 21. Já nos anos de 2003 e 2004 houve um crescimento maior na área de lavouras geneticamente modificadas nos países em desenvolvimento, se comparado com os países industrializados ${ }^{15}$.

Contudo, apenas em março de 2005, a fim de adequar a lei com a realidade existente na plantação de OGM no país, o Presidente Lula sancionou a nova Lei de Biossegurança 11.105, de 24 de mar de 2005, que regulamenta decisivamente o plantio e a comercialização das variedades transgênicas no país ${ }^{16}$.

Após a criação da lei 11.105 de 2005, a disputa pela legitimação da soja transgênica foi encerrada. Apesar disso, as disputas internas a respeito da biotecnologia continuaram, devido à contínua expansão do cultivo de OGM no Brasil e no mundo e à posição de destaque do país nesse cultivo. Como disposto no relatório recente publicado pelo ISAAA, o aumento do cultivo de OGM entre 2007 e 2008 foi de 9,4\% ou 10,7 milhões de hectares. Passando para 25 o número de países que cultivam plantas transgênicas. Além disso, merecem destaque cinco países em desenvolvimento que estão exercendo liderança e incentivando a adoção global das lavouras biotecnológicas, são eles: China, Índia, Argentina, Brasil, e África do Sul ${ }^{15}$. De acordo com esse mesmo relatório, os países que mais plantam OGM são, na ordem: os Estados Unidos, a Argentina e o Brasil, este com 15,8 milhões de hectares. Hoje, são três as plantas transgênicas cultivadas no país: a soja, o milho e o algodão $^{12,15}$. 


\section{O Princípio da Precaução X OGM}

Atualmente, a transgenia ainda é incipiente para proporções amplas de uso, causando riscos reais e imprevisíveis. Sendo assim, grande parte dos cientistas recomenda o princípio da precaução, que visa proteger a vida diante das incertezas científicas. Esse princípio norteia as atividades humanas, incorporando princípios de igualdade, respeito, justiça e prevenção.

O Princípio da Precaução foi formulado primeiramente pelos gregos e, significava ter cuidado e estar ciente. Somente nos anos 70, o Princípio da Precaução foi consolidado na Alemanha, em resposta à poluição industrial, ficando conhecido como Vorsorge Prinzip. Passados 20 anos, esse princípio estava disseminado por toda a Europa. Na década de 1990, uma outra forma de interpretação do Princípio da Precaução foi estabelecida nos Estados Unidos: "É melhor ser grosseiramente certo no tempo devido, tendo em mente as consequências de estar sendo errado do que ser completamente errado muito tarde". Atualmente, o Princípio da Precaução vem sendo aplicado em todas as áreas da economia que podem, de alguma maneira, causar danos à saúde humana e ao meio ambiente ${ }^{17}$.

No Brasil, em 1992, o Princípio da Precaução foi abordado na Conferência do Rio de Janeiro e consolidado como princípio 15 da Agenda 21, tendo como finalidade, proteger o meio ambiente diante do perigo grave ou irreversível ${ }^{18}$.

Em vista da polêmica ao redor dos transgênicos, conforme citado anteriormente, foi elaborado em Janeiro de 2000, em Montreal, o Protocolo Internacional de Biossegurança, também denominado de Protocolo de Cartagena, com o objetivo de: "contribuir para a garantia de um nível adequado de proteção à transferência, manipulação e utilização segura dos organismos vivos modificados resultantes da biotecnologia moderna que possam ter efeitos adversos na conservação e na utilização sustentável da diversidade biológica, levando-se em conta os riscos para a saúde humana" ${ }^{19}$.

Dessa maneira, esse princípio defende a ideia de que diante da ausência da certeza científica, a existência do risco de um agravo demanda a implantação de medidas que possam prevenir este agravo. Ou seja, ao legislar sobre uma ciência ainda não conhecida, deve-se ser precavido.

Nodari e Guerra ${ }^{20}$ relatam que para uma tecnologia com grande potencialidade de uso, mas cujos riscos ainda não foram avaliados de forma adequada, o princípio da precaução é, sem dúvi- da, a atitude mais ponderada. No trabalho de Valle $^{3}$, são levantados dados da Associação Médica Inglesa que considerava prematura a introdução de alimentos transgênicos na Inglaterra devido à insuficiência de dados sobre a segurança da produção de AGM. Para Goldim² ${ }^{21}$ o princípio da precaução representa a garantia contra os riscos potenciais que ainda não podem ser identificados.

Ainda hoje, pesquisas e estudos que envolvem os potenciais riscos ao consumo humano de AGM ainda são muito restritos. No entanto, existem estudos sobre o efeito da ingestão de soja Roundup Ready em ratos, que demonstraram em análises ultraestruturais e imunocitoquímica, alterações em células acinares do pâncreas (redução de fatores de "splicing" do núcleo e do nucléolo e acúmulo de grânulos de pericromatina); em testículos (aumento do número de grânulos de pericromatina, diminuição da densidade de poros nucleares e alargamento do retículo endosplasmático liso das células de Sertoli), havendo a possibilidade de tais efeitos estarem relacionados ao acúmulo de herbicida presente na soja resistente, além de alterações em hepatócitos (modificações na forma do núcleo, aumento do número de poros na membrana nuclear, alterações na forma arredondada do nucléolo, indicando aumento do metabolismo) sendo potencialmente reversíveis neste último grupo de células ${ }^{21-25}$.

No Brasil, existe uma carência de pesquisas sobre os transgênicos ${ }^{26}$. A falta de informação pode estar relacionada com a falta de problematização no espaço acadêmico sobre as inovações tecnológicas que envolvem riscos incertos. Consequentemente há carência de dados sobre a opinião pública, expondo o mesmo na área do marketing.

Para atender o Princípio da Precaução, a liberação de AGM deve atender ás necessidades de informação e segurança do cidadão consumidor, sendo imprescindível que a avaliação da segurança desse produto aconteça antes da sua introdução no mercado de consumo ${ }^{27}$.

\section{Rotulagem como elemento de informação}

A rotulagem é imprescindível aos alimentos. É através dos rótulos que os consumidores podem conhecer o produto que estão comprando e entender o que está sendo informado. Nesse caso, o rótulo funciona como um veículo de informação. Além de fornecer segurança ao consumidor, também proporciona uma diferenciação de marketing de um produto/marca para outro. 
A legislação brasileira tem como base para a rotulagem o Codex Alimentarius, principal órgão internacional responsável pelo estabelecimento de normas sobre a segurança e a rotulagem dos alimentos, assim, define rótulo como: "toda inscrição, legenda ou imagem, ou toda matéria descritiva ou gráfica, escrita, impressa, estampada, gravada em relevo ou litografada ou coletada sobre a embalagem do alimento". Através da rotulagem pode-se rastrear os produtos, constituindo-se numa ferramenta essencial para a saúde pública brasileira. Como prevê o Código de Defesa do Consumidor (CDC), por meio da rotulagem é possível rastrear o alimento, pois em caso de efeito adverso na saúde humana, os produtos rotulados seriam facilmente identificados e recolhidos. O CDC garante, ao cidadão, o direito da informação sobre o produto através do rótulo, disposto de forma clara e adequada, que deverá ainda expor corretamente os seguintes tópicos: quantidade, características, composição, qualidade e preço, bem como os riscos que apresentem ${ }^{28}$. Dessa forma permite ao cidadão o direito de escolha sobre o consumo ou não do produto.

Para os produtos derivados de OGM a rotulagem também deve ser aplicada, pois, torna-se mais do que imprescindível, havendo a necessidade vital de informações detalhadas acerca da relação entre a exposição e seus efeitos - que ainda é incipiente. Sendo assim, em 2003, quando a soja transgênica foi liberada para plantio e comercialização, entrando como consequência na cadeia alimentar dos brasileiros, emerge uma polêmica que diz respeito ao direito do consumidor: a garantia de ter acesso à informação no rótulo do alimento que consome ${ }^{29}$.

Com o objetivo de disciplinar a rotulagem de alimentos geneticamente modificados, obrigando a publicação de informações no rótulo desses produtos, foi criado o Decreto no 3.871 de 2001. Este estabelece que a rotulagem para produtos alimentares de consumo humano, embalados e que apresentem no mínimo $4 \%$ de produtos geneticamente modificados. E no caso de alimentos com mais de um ingrediente geneticamente modificado em sua composição, a tolerância era estabelecida a cada um desses ingredientes isoladamente; além de isentar a rotulagem dos produtos in natura e produtos nos quais a presença de organismos geneticamente modificados não fosse detectada ${ }^{30}$. Posteriormente, o Decreto No 3.871 de 2001 foi revogado pelo Decreto 4.680 de 2003. Neste novo decreto, em virtude de críticas feitas por organizações de defesa dos direitos do consumidor à legislação anterior, a rotulagem foi estendida para todos os alimentos embalados, a granel ou in natura, que contenham mais de $1 \%$ de transgenicidade em sua composição, inclusive para alimentos de origem animal que possuírem transgênicos em sua composição; além de exigir a identificação da espécie doadora do gene, da indicação de uma das seguintes expressões: "(nome do produto) transgênico", "contém (nome do ingrediente ou ingredientes) transgênico(s)" ou "produto produzido a partir de (nome do produto) transgênico" ${ }^{31}$.

Em 2003, além da substituição do Decreto No 3.871 de 2001 pelo Decreto 4.680 de 2003, foi criado o símbolo do transgênico. O qual deve constar nas embalagens de produtos transgênicos ou em seus derivados destes que, se encontram em situação conforme prevista pela Portaria no 2658, de 22 de dezembro de $2003^{31}$.

A legislação de rotulagem dá ao consumidor o direito à informação, permite o rastreamento e o controle pós-comercialização de produtos alimentares. Dessa maneira possibilita o controle da qualidade de alimentos.

Para que a rotulagem de alimentos sirva como orientação ao consumidor sobre a qualidade e a quantidade dos constituintes nutricionais dos produtos, possibilitando a escolha alimentar mais apropriada, as informações devem ser corretas e fidedignas, o que impacta na adoção de práticas alimentares e no estilo de vida saudáveis ${ }^{32}$. Podemos dizer que a aplicação da rotulagem de forma adequada é um Princípio da Precaução. No entanto, compete a Agência Nacional de Vigilância Sanitária (ANVISA) garantir que as informações presentes nos rótulos estejam de acordo com o conteúdo desses produtos e com a legislação em vigor.

A ANVISA é responsável por fiscalizar a produção e a comercialização dos alimentos brasileiros, além de normatizar a rotulagem dos mesmos. Dentre os produtos que são submetidos ao controle de fiscalização sanitária pela ANVISA, merecem destaque os produtos com possibilidade de risco à saúde, obtidos por engenharia genética, dos quais fazem parte os $\mathrm{AGM}^{33}$.

No entanto, para que as ações da ANVISA possam ser cumpridas é necessário dispor de laboratórios para a realização da análise de detecção/quantificação dos alimentos derivados de OGM que se encontram nas prateleiras dos supermercados ${ }^{27}$.

Estudos recentes realizados no Brasil revelam as dificuldades e/ou o não cumprimento da lei de rotulagem de alimentos derivados de OGM e apontam o método de análise por "Polymerase 
Chain Reaction" (PCR) como o mais eficaz na detecção de OGM em alimentos, sendo, portanto, o mais utilizado em laboratórios ${ }^{10,27,34,35}$.

Na pesquisa de Greiner e Konietzny ${ }^{11}$, foram analisados 100 alimentos derivados de soja entre 2000 e 2005. Em 2000, 11\% desses alimentos possuíam soja acima de $1 \%$ do total dos ingredientes. Porém, em 2005, esse número aumentou para $36 \%$. Esse estudo revela que nenhum desses alimentos estavam devidamente rotulados, ou seja, não cumpriam com a legislação em vigor.

Câmara et al. ${ }^{32}$ apontam as dificuldades de compreensão das informações disponibilizadas nos rótulos pelos cidadãos consumidores, pois na maioria das vezes não são claras, ou são tendenciosas, levando o consumidor ao engano. $\mathrm{Da}$ mesma forma, as informações sobre OGM, quando existentes, são mínimas, e outro problema evidenciado é a falta de conhecimento da população brasileira sobre os transgênicos ${ }^{21}$.

\section{A sociedade e os OGM}

O polêmico tema "transgênicos" envolve opiniões divergentes onde, de um lado, setores da sociedade defendem arduamente o uso extensivo dessa tecnologia, enquanto que, por outro lado, setores repudiam o seu uso sem antes ser realizado um estudo longo e detalhado dos impactos que o plantio e o consumo desses alimentos possam trazer para a saúde humana e para o meio ambiente. Assim, as grandes empresas de biotecnologia quando falam dos impactos dos transgênicos, concluem que não há diferenças em relação às plantas convencionais, quando o assunto é segurança e riscos. Porém, em se tratando de propriedade intelectual, essas mesmas empresas assumem as grandes diferenças das plantas geneticamente modificadas, a fim de obter patente e de cobrar royalties pelo uso das sementes ${ }^{3}$.

Nodari e Guerra ${ }^{19}$ vão além quando dizem que, se por meio de lavouras demonstrativas, da mídia ou de outros meios tenta-se convencer os agricultores das grandes vantagens e das características únicas das plantas transgênicas, ao mesmo tempo o argumento usado junto aos consumidores é o de que os produtos derivados dessas plantas são similares aos obtidos das convencionais. Enquanto de um lado os centros de biotecnologia e os agricultores defendem o uso indiscriminado dos transgênicos nas lavouras, do outro lado, organizações não governamentais e alguns setores do governo travam uma verdadeira batalha em defesa de estudos mais detalhados sobre os efeitos que essas modificações nos alimentos poderão causar no organismo dos seres humanos e na biodiversidade do planeta. Dessa maneira, a lei de Biossegurança é focada em favor dos interesses de cada setor envolvido.

No Brasil, essa polêmica se agravou quando o governo, que dizia apoiar o Principio da Precaução, liberou, em 2005, a comercialização da soja transgênica. Vale ressaltar que, no momento da liberação, os efeitos do uso de alimentos geneticamente modificados na saúde humana e no meio ambiente ainda não eram reconhecidos nem mensurados pela comunidade científica ${ }^{36}$.

Uma das instituições que estão nessa guerra é o Instituto de Defesa do Consumidor (IDEC) que, representando os consumidores nesta rodada de negociações, sugerem que apareça no rótulo não só a expressão "produto transgênico", mas também a característica e o nome do organismo doador do gene ${ }^{37}$.

O Instituto Brasileiro de Defesa do Consumidor é uma associação de consumidores fundada em 1987. Não possui fins lucrativos e não tem vínculo com empresas, governos ou partidos políticos. Seu objetivo é o de orientar e informar os consumidores sobre os seus direitos, atuando em questões de grande relevância e interesse coletivo da sociedade, como no caso dos OGM, utilizando como instrumento o Código de Defesa do Consumidor (CDC), a fim de buscar o fortalecimento da cidadania e de uma sociedade mais justa ${ }^{38}$.

Outro órgão que merece destaque é o Conselho Nacional do Meio Ambiente (Conama), órgão pertencente ao Sistema Nacional do Meio Ambiente (Sisnama), sendo um colegiado representativo de cinco setores: órgãos federais, estaduais e municipais, setor empresarial e sociedade civil, que vem interferindo na questão dos OGM no país.

O Conama, juntamente com o Idec e outras organizações, aprovou, em junho de 2002, a Resolução n’ 305. Esta "disciplina os critérios e os procedimentos a serem observados pelo órgão ambiental competente para o licenciamento ambiental de atividades e empreendimentos que façam uso de Organismos Geneticamente Modificados (OGM) e derivados, efetiva ou potencialmente poluidores, nos termos do art. $8^{\circ}$, da Lei no 6.938 , de 31 de agosto de 1981, e, quando for o caso, para elaboração de Estudos de Impacto Ambiental (EIA) e respectivo Relatório de Impacto no Meio Ambiente (Rima), sem prejuízo de outras Resoluções ou normas aplicáveis à matéria”.

Assim como o Idec, o Greenpeace - organização global e independente que atua para defender o meio ambiente e promover a paz, inspiran- 
do as pessoas a mudarem atitudes e comportamentos - faz campanha contra a liberação de OGM no meio ambiente e se opõe ao seu uso na alimentação humana e animal. Para a organização, os resultados da utilização de transgênicos, sem que estudos suficientes que comprovem a sua segurança sejam realizados, são imprevisíveis, incontroláveis e desnecessários. O Greenpeace advoga a favor do Princípio da Precaução sobre a questão dos transgênicos ${ }^{14}$.

Como exemplo de atuação do Greenpeace, em 2005, o mesmo, denuncia alguns óleos de cozinha fabricados pelas empresas Bunge e Cargil, pois continham soja transgênica e não usavam o triângulo amarelo em seus rótulos, como prevê a legislação brasileira, o que levou o Ministério Público a iniciar um processo jurídico para obrigar essas empresas a se adequarem à legislação e a informarem seus clientes sobre a presença de transgenia. Além disso, como ainda há várias empresas que usam ingredientes transgênicos e não informam o consumidor sobre isso, desrespeitando o direito de informação, previsto no CDC, o Greenpeace produziu o 'Guia do Consumidor'. Na publicação, há uma lista de produtos que podem conter transgênicos e de produtos sem transgênicos, cujo objetivo é permitir aos cidadãos brasileiros uma escolha mais consciente ${ }^{39}$.

Como podemos notar, a sociedade civil organizada brasileira desempenhou um papel que caberia ao Estado, pois lideraram estratégias e ações de cumprimento da decisão judicial que proibia o plantio e a comercialização dos transgênicos no país.

Segundo Furnival e Pinheiro ${ }^{40}$, apesar de haver ainda hoje no Brasil pouco conhecimento sobre os OGM, manifesta-se a vontade de haver informações sobre a presença desses componentes nos alimentos antes de sua compra. Além disso, revela que há escassez de pesquisas qualitativas no Brasil que tratem da compreensão do público a respeito das informações sobre novas tecnologias, incluindo os OGM.

A população anseia por poder voltar a confiar num sistema regulador que se oriente pelo bem comum da humanidade e por uma noção mais ampla da ciência. Conceito este em que o conhecimento não seja reduzido, sem espaço para questionamentos acerca de sua sustentabilidade socioambiental. Pois, atualmente, é só da comunidade científica que pode partir a ousadia para desconstruir a polêmica sobre os transgênicos ${ }^{41}$.

Guivant ${ }^{26}$ comprova em seu estudo que os fatores culturais afetam a forma como as pessoas estimam os riscos, podendo ser apoiados em suas experiências e julgamentos de credibilidade e confiança em relação às instituições reguladoras de riscos. Para tanto, a população deve ser estimulada a diversas opiniões sobre a compreensão do desenvolvimento científico e tecnológico, de uma maneira que evite interpretações tendenciosas que exclusivamente confirmem argumentos que determinados grupos sociais, políticos ou econômicos, que encomendam as pesquisas, querem legitimar.

O cidadão consumidor é um componente extremamente importante no processo de liberação comercial destes produtos. Onde a aceitação pública significa a atitude dos indivíduos sobre os aspectos originários de inovações tecnológicas, dependente da percepção individual dos benefícios e riscos de uma tecnologia, de valores sociais, da confiança nas instituições que representam estas tecnologias, e das fontes de informação.

Como descreve Spendeler ${ }^{42}$, a engenharia genética, tecnologia nova e capaz de produzir seres vivos que nunca foram obtidos mediante mecanismos naturais, introduz um fator importante de "insegurança alimentar" pela sua imprevisibilidade, instabilidade e, como consequência, a incerteza que lhes são inerentes.

\section{Conclusão}

Hoje vivemos em uma época marcada pela supremacia da ciência e da tecnologia, onde existem muitas incertezas que deverão ser asseguradas para garantir um futuro sustentável à humanidade. Sem dúvida a biotecnologia é uma conquista científica, porém, não está isenta de ônus.

$\mathrm{O}$ apogeu das biotecnologias nos diversos campos de sua utilização mostra-se muito promissor, portanto, o conhecimento científico não deve ser impetuoso, causando desequilíbrios genéticos, nem tampouco a sociedade deve abdicar do seu avanço científico.

Como vimos anteriormente, a informação é um direito do cidadão, sendo um requisito imprescindível para poder aumentar o poder decisório dos mesmos, e não para diminuir o fosso existente entre o público e os setores favoráveis e contrários aos transgênicos.

A ciência enfatiza o papel da informação como comunicação para a superação do fosso, mas recentemente tem sido identificado com déficit. Pois, os leigos são identificados como receptores passivos de estímulos independentes, percebendo os riscos de forma não científica, pobremente informada e irracional. 
Vale ressaltar que "nada na vida é livre de riscos", quando asseguramos um produto como sendo seguro estamos considerando os seus limites aceitáveis de risco.

Acreditamos que as investigações sobre a biossegurança dos AGM deveriam ser absolutamente prioritárias, aplicando-se os instrumentos essenciais da ciência para esboçar um futuro mais equitativo e menos assimétrico.

Ainda que a Lei de Biossegurança afirme adotar o Princípio da Precaução para a proteção da saúde humana, animal, vegetal e do meio ambiente, nem todos os órgãos governamentais ligados diretamente à questão trabalham a partir desse princípio. No caso da Comissão Técnica nacional de Biossegurança (CTNBio), órgão do governo que libera a comercialização dos alimentos transgênicos, nem sempre tem o compromisso com a população de colocar a saúde acima de questões econômicas.
As investigações sobre a segurança dos AGM deveriam ser absolutamente prioritárias, uma vez que as normas de rotulagem existentes não são suficientes para que a comercialização de produtos que contêm OGM seja liberada pela CTNBio, cuja ação precede a atuação dos demais órgãos reguladores - Anvisa e Ministério da Agricultura.

A segurança alimentar é de suma importância para o desenvolvimento da sociedade e esta tem como direito o acesso à composição dos alimentos que consome providenciado de forma clara e segura, como disposto nas leis, normas e decretos acima citados. Para tanto é premente que se estabeleça uma política nacional de biossegurança que instrumentalize e envolva a sociedade civil organizada e todos os órgãos do governo responsáveis pela fiscalização. Afinal, cabe ao Estado, com todos os mecanismos de que dispõe, agir em defesa do direito constitucional à saúde.

\section{Colaboradores}

IG Ribeiro e VA Marin participaram igualmente de todas as etapas de elaboração do artigo. 


\section{Referências}

1. Prudente AS. Transgênicos, biossegurança o Princípio da Precaução. R CEJ 2004; 25:77-79.

2. Food and Agriculture Organization. Committee on Agriculture. Biotechnology. [serial on the Internet]. 1999 Jan [cited 2009 Jul 20]; [about 5p.]. Available from: http://www.fao.org/unfao/bodies/COAG

3. Valle S. Transgênicos sem maquineísmo. Hist Cienc Saude Manguinhos 2000; 7(2):493-498.

4. Bull AT, Lilly MD. Organização de Cooperação e Desenvolvimento Econômico (OECD). Biotecnology, Internacional Trends and Perspectives. 1992. [acessado 15 jan 2008]. Disponível em: http://www.oecd. org/dataoecd/34/9/2097562.pdf

5. Brasil. Ministério da Ciência e Tecnologia. Programa de Biotecnologia e Recursos Genéticos, 2002. [acessado 2008 jan 12]. Disponível em: http:// www.abrasil.gov.br/avalppa/site/content/av_prog/ 12/01/prog1201.htm

6. Nodari RO, Guerra MP. Plantas Transgênicas e seus Produtos: Impactos, Riscos e Segurança Alimentar (Biossegurança de Plantas Transgênicas). Rev Nutr 2003; 16(1):105-116.

7. Monquero PA. Plantas transgênicas resistentes aos herbicidas: situação e perspectivas. Bragantia 2005; 64(4):517-531.

8. Villen RA. Biotecnologia - histórico e tendências. [homepage na Internet]. [acessado 2009 jan 27]. Disponível em: http://www.hottopos.com/regeq10/ rafael.htm.

9. Chiarello MD, Guerroué JL, Valadão F. A Importância da Rastreabilidade: O Caso dos Alimentos Transgênicos. Hig Alimen 2004; 8(126/127):14-18.

10. Cardarelli P. Branquinho MR. Ferreira RTB, Cruz FC. Gemal AL. Detection of GMO in food products in Brazil: the INCQS experience. Food Control 2005; 16(10):859-866

11. Germini A, Zanetti A, Salati C, Ross S, Forré C, Schimid S, Marchelli R, Fogher C. Development of a seven-target multiplex PCR for the simultaneous detection of transgenic soybean and maize in feeds and foods. J Agric Food Chem 2004; 52(11):3275-3280.

12. Castro BS. A introdução no Brasil do algodão, milho e soja geneticamente modificados: coincidências reveladoras. [Apresentação no Congesso BRASA IX Tulane University; 2008 mar 27-29; Louisiana, New Orleans].

13. Menasche R. Os grãos da discórdia e o trabalho da mídia. Opin Públic 2005; 11(1):169-191.

14. Greenpeace [homepage na Internet]. O contexto político dos transgênicos no Brasil. 2005 [acessado 2009 fev 12]. Disponível em: http://www.greenpeace.org/ raw/content/brasil/documentos/transgenicos/ greenpeacebr_050430_transgenicos_documento_ contexto_politico_port_v1.pdf.

15. Serviço Internacional para a Aquisição de Aplicações em Agrobiotecnologia (ISAAA). Situação Global das Culturas Biotecnológicas/GM Comercializadas. 2008. [acessado 2009 ago 28]. Disponível em: http://64. 233.163.132/translate_c?hl=ptBR\&langpair $=$ en $\% 7 C$ $\mathrm{pt \& u}=\mathrm{http} / / / \mathrm{www}$.isaaa.org/resources/publications/ briefs/39/executivesummary/pdf/Brief\% $252039 \% 2$ $520 \% 2520$ Executive $\% 2520$ Summary $\% 2520 \% 2520$ Portuguese.pdf\&rurl=translate.google.com\&usg=ALkJrhgL M3Kybx2Y9doRnJmrxGKlr016Cw.
16. Brasil. Casa Civil. Lei no ${ }^{\circ} .11105$, de 24 de Março de 2005. Regulamenta os incisos II, IV e V do $\$ 1$ o do art. 225 da Constituição Federal, estabelece normas de segurança e mecanismos de fiscalização de atividades que envolvam organismos geneticamente modificados - OGM e seus derivados, cria o Conselho Nacional de Biossegurança - CNBS, reestrutura a Comissão Técnica Nacional de Biossegurança - CTNBio, dispõe sobre a Política Nacional de Biossegurança - PNB, revoga a Lei no 8.974, de 5 de janeiro de 1995, e a Medida Provisória no 2.191-9, de 23 de agosto de 2001, e os arts. 5o, 6o, 7 o, $80,90,10$ e 16 da Lei no 10.814 , de 15 de dezembro de 2003, e dá outras providências. Diário Oficial da União 2005; 28 de mar.

17. Nodari RO. Pertinência da ciência precaucionária na identificação dos riscos associados aos produtos das novas tecnologias. 2005 [acessado 2009 jan 8]. Disponível em: http://www.ghente.org/etica/ principio_da_precaucao.pdf

18. Organização das Nações Unidas (ONU). Declaração sobre o Meio Ambiente e Desenvolvimento. Conferência das nações Unidas sobre o Meio

19. Ambiente e Desenvolvimento [evento na Internet]. 1992 jun 3-21; Rio de Janeiro, Brasil. [acessado 2009 jan 26]. Disponível em: http://pfdc.pgr.mpf.gov.br/ conteudotematico/confnacionaldedireitoshumanos/ documentos/instrumentosinternacionais/Declarac 255 eo $\% 20$ sobre $\% 20$ Meio $\% 20$ Ambiente $\% 20$ e $\% 20$ Desenvolvimento.pdf.

20. Nodari RO, Guerra MP. Implicações dos transgênicos na sustentabilidade ambiental e agrícola. Hist Cienc Saude Manguinhos 2000; 7(2):481-491.

21. Goldim JR. O Princípio da Precaução. 2002 [acessado 2009 jan 15]. Disponível em: http://www.bioetica. ufrgs.br/precau.htm

22. Costa TEMM, Dias APM, Marin VA. Avaliação de Risco dos Organismos Geneticamente Modificados. Cien Saud Colet 2007; 16(1):327-336.

23. Malatesta M, Biggiogera M, Manuali E, Rocchi MBL, Baldelli B, Gazzanelli G. Fine structural analyses of pancreatic acinar cell nuclei from mice fed on genetically modified soybean. Eur J Histochem 2003; 47(4):385-388.

24. Malatesta M, Caporaloni C, Rossi L, Battistelli S, Rocchi MBL, Tonucci F, Gazzanelli G. Ultrastructural analysis of pancreatic acinar cells from mice fed on genetically modified soybean. J Anat 2002; 201(5):409-415.

25. Malatesta M, Tiberi C, Baldelli B, Battistelli S, Manuali E, Biggiogera M. Reversibility of hepatocyte nuclear modifications in mice fed on genetically modified soybean. Eur J Histochem 2005; 49(3):237242.

26. Vecchio L, Cisterna B, Malatesta M, Martin TE, Biggiogera M. Ultrastructural analysis of testes from mice fed on genetically modified soybean. Eur $J$ Histochem 2004; 48(4):449-454.

Guivant, JS. Transgênicos e percepção pública da ciência no Brasil. Ambient \& Socied 2006; 9(1):82103. 
27. Barros NEF, Oliveira EMM, Marin VA. Aplicabilidade da metodologia de reação de polimerase em cadeia em tempo real na determinação do percentual de organismos geneticamente modificados em alimentos. Rev. Nutri. 2008; 21(1):85-92.

28. Brasil. Casa Civil. Lei $n^{\circ}$. 8078, de 11 de setembro de 1990. Dispõe sobre a proteção do consumidor e dá outras providências. Diário Oficial da União 1990; 12 set.

29. Instituto de Defesa do Consumidor [homepage na Internet]. Idec comenta novo decreto de rotulagem dos transgênicos. 2003. [Documento da Internet] [acessado 2009 fev 5]. Disponível em: http://www. idec.org.br/emacao.asp?id=344

30. Brasil. Casa Civil. Decreto ${ }^{\circ}$. 3871, de 18 de julho de 2001. Disciplina a rotulagem de alimentos embalados que contenham ou sejam produzidos com organismos geneticamente modificados. Diário oficial da União 2001; 19 jul.

31. Brasil. Casa Civil. Decreto ${ }^{\circ}$. 4680, de 24 de abril de 2003. Regulamenta o direito à informação, assegurado pela Lei $n^{\circ} .8 .078$, de 11 de setembro de 1990, quanto aos alimentos e ingredientes alimentares destinados ao consumo humano ou animal que contenham ou sejam produzidos a partir de organismos geneticamente modificados. Diário Oficial da União 2003; 25 abr.

32. Câmara MCC, Marinho CLC, Guilam MC, Braga AMCB. A Produção Acadêmica sobre a Rotulagem de Alimentos no Brasil. Rev Panam Salud Publica 2008; 23(1):52-57.

33. Brasil. Agência Nacional de Vigilância Sanitária (Anvisa). Lei nº. 9782, de 26 de janeiro de 1999. Define o Sistema Nacional de Vigilância Sanitária, cria a Agência Nacional de Vigilância Sanitária. Diário Oficial da União 1999; 27 jan.

34. Dinon AZ, Melo JE, Arisi ACM. Monitoring of MON 910 genetically modified maize in foods in Brazil from 2005 to 2007. J Food Compost Anal 2008; 21:515-518.
35. Greiner R. Konietzny U. Presence of genetically modified maize and soy in food products sold commercially in Brazil from 2000 to 2005. Food Control 2008;19(5):499-505.

36. Lewgoy F. A voz dos cientistas críticos. Hist Cienc Saude Manguinhos 2000; 7(2):503-508.

37. Instituto de Defesa do Consumidor. [homepage na Internet]. Direito à informação e alimentos transgêenicos. 2008. [Documento da Internet] [acessado 2009 mar 4]. Disponível em: http://www.idec.org.br/ noticia.asp?id=11326.

38. Instituto de Defesa do Consumidor [homepage na Internet]. Definição do IDEC. 2009. [Documento da Internet] [acessado 2009 mar 4]. Disponível em: http://www.idec.org.br.

39. Greenpeace [homepage na Internet]. Guia do consumidor. 2004. [Documento da Internet] [acessado 2009 fev 12]. Disponível em: http://www.greenpeace. org/brasil/transgenicos/consumidores

40. Furnival AC, Pinheiro SM. A percepção pública da informação sobre os potenciais riscos dos trângenicos na cadeia alimentar. Hist Cienc Saude Manguinhos 2008; 15(2):277-291.

41. Leite M. Arautos da razão: a paralisia no debate sobre transgênicos e meio ambiente. Nov Estud Cebrap 2007; 78:41-47.

42. Spendler L. Organismos modificados genéticamente: uma nueva amenaza para la seguridad alimentaria. Rev Esp Salud Públic 2005; 79(2):271-282.

Artigo apresentado em 19/04/2010

Aprovado em 02/08/2010

Versão final apresentada em 25/08/2010 